\title{
Crisis Decision Making Through a Shared Integrative Negotiation Mental Model
}

\author{
Willem van Santen \\ TU Delft / Peak \& Valley \\ w.van.santen@peakandvalley.nl
}

\author{
Catholijn Jonker \\ TU Delft \\ c.m.jonker@tudelft.nl
}

\author{
Niek Wijngaards \\ D-CIS Lab / Thales Research \& Technology Netherlands \\ niek.wijngaards@icis.decis.nl
}

\begin{abstract}
Decision making during crises takes place in (multi-agency) teams, in a bureaucratic political context. As a result, the common notion that during crises decision making should be done in line with a Command \& Control structure is invalid. This paper shows that the best way for crisis decision making teams in a bureaucratic political context is to follow an integrative negotiation approach as the shared mental model of decision making. This conclusion is based on an analysis of crisis decision making by teams in a bureaucratic political context. First of all this explains why in a bureaucratic political context the Command \& Control adage does not hold. Secondly, this paper motivates why crisis decision making in such context can be seen as a negotiation process. Further analysis of the given context shows that an assertive and cooperative approach suits crisis decision making best.
\end{abstract}

\section{Keywords}

Shared Mental Models, Crisis Management Decision Making, Negotiation.

\section{INTRODUCTION}

There are no hard and objective criteria that exactly define when a crisis is at hand. People use the word crisis to characterize situations or epochs that they somehow regard as extraordinary, volatile, and potentially farreaching in their negative implications (Boin et. Al, 2005, p137-138). Rosenthal states that a crisis is a serious threat of the basic infrastructures or of fundamental values and norms of a social system. During a crisis, little time for decision making and a high level of uncertainty enforce the making of critical decisions (Rosenthal, 1984, p.25).

Traditionally, crisis management is handled from a net-centric point of departure (van de Ven et al., 2008, the Netherlands department of the interior en kingdom relations 2008, Alberts and Hayes, 2005, pp. 201-222). In this view the crisis management is best represented as a network of actors that cooperate to achieve common goals. In that network, there is a commander in chief that commands and controls the actions of the actors in the network. To be able to operate successfully in a networked crisis context, several conditions should be fulfilled. For instance, it is important that every actor has actual and correct information, that the information is shared among all actors, that there are shared (common) goals and that actors are willing and able to work together to achieve those goals (van Santen et al, 2007; Alberts and Hayes, 2005).

Although there is a number of constant factors that characterize crises (Wybo and Latier, 2006), the nature of crises has changed over the years (Robert and Laitha, 2002). The regional scope of crises is getting larger and crises are politiziced ('t Hart et al., 2001). To adapt to these changes and to improve the quality of the decisions during a crisis and the speed of the crisis decision making process, tools and techniques have been and are being developed to route the right information to the right place at the right time. This is done to avoid information overload of the human decision makers. Typically, these tools and techniques have a netcentric point of departure.

Evaluations of crises, however, time and again show that in and between crisis teams these netcentric conditions are not met. It appears that there is no real multidisciplinary coordination or cooperation, goals are diverse and often not shared, information is not accessible and information systems are not optimally used (Rosenthal, 1984, Rosenthal et al., 1991, Boin et al., 2005, Helsloot, 2008). Analysis of Dutch crisis management procedures have shown that rules and regulations are suboptimal for good performance of crisis management teams Boogers et 
al, 2003; Scholten, 2008). From the above, it can be concluded that there is a need to optimize the way crises are handled.

This paper focuses on crisis decision making on the above-operational levels. We argue that crisis decision making takes place in multi agency (multi disciplinary) teams in a bureaucratic political context. In a bureaucratic political reality, there is no unity of command. The multi-agency crisis management teams have characteristics of self-managing teams. For instance, such teams have no hierarchical team leader. Furthermore, we observe that in crisis decision making, although there is a common (often abstract) interest to solve the crisis, the individual interests can be so diverse that they lead to conflicting preferences and actions of participating organizations. Finally, we observe that in a crisis decision making process, each team member tends to address his ${ }^{1}$ own convictions, responsibilities, goals and resources. In practice, shared or collaborative problem analysis seldom takes place (van Santen et al., 2007). Based on these observations we conclude that the Command \& Control adage does not hold for these multi-agency teams.

For the above-operational levels, this paper investigates the value of multi-issue, multi-party negotiation as a description of crisis decision making in bureaucratic political context. Our analysis shows that crisis decision making in bureaucratic political context can indeed be seen as a negotiation process. As a result an assertive and cooperative approach is best suited, and crisis decision making teams should have a shared integrative model of negotiation as their dominant and shared team model of crisis decision making.

To support these claims this paper is constructed as follows. The first section focuses on bureaucratic politics in crisis management with observations from Dutch crisis management experiences. The section "A Negotiation Perspective of Crisis Decision Making" provides an analysis of crisis decision making, and emphasizes useful contributions from the negotiation field of research to crisis decision making. The section "Mental Models in Collaborative Decision Making" defines the notion of (shared) mental models in crisis decision making. The section "Mental Models of Negotiation in Crisis Decision Making" combines the notion of shared mental models for decision making in crisis decision teams with that of the appropriate negotiation theories to propose a description of a team process of crisis decision in a bureaucratic political context that is based on integrative bargaining and shared mental models. The concluding section also presents some further lines of research.

\section{BUREAUCRATIC POLITICS IN CRISIS MANAGEMENT}

During crises, decision making processes tend to get centralized. Crisis management operations are performed on the operational level and above that operational level several decision making teams are active to analyze the situation and decide on what actions should be taken at what time. The decision making teams operate in a hierarchical structure. Each decision making team has a team leader. The team leader reports to a team leader on the next organizational level. So, for every crisis there is a suitable command and control structure with a single commander in chief at the top. The command and control approach is generally accepted as the best way to deal with time critical and complex problems.

In practice, we feel that there are features of crisis management decision making that prevent the proper working of the command and control approach. First of all, the changing nature of crises (i.e. de-regionalization and politization) demand a coordination approach of crisis management decision making (Boin et al., 2005 p 147, Helsloot 2008, Scholten, 2008). Secondly, crisis management decision making during crises takes place in (multi-agency) teams (Devitt, 2008, Boin et al., 2005, p.12). The members of these teams do not know each other very well and do certainly not work together very often. There is no hierarchical relationship between the team members and the team leader. Thirdly, the decision making process (above operational level) is spread among a number of interested parties: small crisis teams or policy centers, advisors, interest groups, etc (Rosenthal et al. 1991, 't Hart et al. 1993, Devitt and Borodzicz, 2008, Boin et al. 2005, p. 12, p. 43). In the multi-agency environment where the crisis takes place, every actor can have a different perception of the size, nature and content of the threat and the time constraints the crisis imposes. In fact, what some see as a threat others see as an opportunity (Rosenthal et al. 1991, 't Hart et al., 1993). According to Rosenthal, there is little evidence for the assumption of consensus, unanimity and solidarity in managing crises. Based on these observations, we conclude that the command and control perspective cannot represent the practice of crisis management decision making.

The main organizations involved in crisis management, i.e. police organizations or fire brigades, communities, government agencies, government departments) have a bureaucratic nature. Holsti states that in a bureaucratic environment the decision making process is heavily constrained by legal and formal norms (Holsti, 1990, 118). These constraints enhance the rationality of decision making, but also have some disadvantages. One of these

\footnotetext{
1 'His' should be interpreted as 'his/her'. 
disadvantages is the existence of parochial perspectives ${ }^{2}$ (where you 'stand' depends on where you 'sit'). Team members feel themselves representatives of their own organizations, and not primarily member of the team. Rosenthal has developed a theory about the way government agencies interact: bureaucratic politics, or bureaupolitics. Bureaupolitical behavior takes place in the following environment (Rosenthal et al. 1991, Rosenthal et al. 1987, Pröpper 1993):

1. many actors in the policy-making arena

2. actors have diverging and conflicting interests

3. no one actor has overriding influence

4. decisions are inherently compromises

5. the decision outcomes tend not to anticipate the requirements for effective implementation.

According to (Rosenthal et al, 1991), bureaupolitical behavior also takes place in crisis management. And the behavior that Rosenthal described in 1991 still fits the current practice of crisis management (Boin et al, 2005, pp 48-49); Scholten, 2008; Brainich von Brainich Felt, 2004). To illustrate this, we have presented in figure 1 a short empirical scan of Dutch Crisis Management experiences. This scan indicates that the above mentioned conditions for bureaucratic political behavior are still met. As there seems to be no formal and univocal hierarchy in crisis management situations, the decision making process should be based on a coordination approach. In that process of coordination, we have to accommodate that participants show bureaupolitical behavior $^{3}$.

\section{An empirical scan of Dutch Crisis Management}

In June 2004, the Dutch Government presented a policy plan for improving crisis management in the Netherlands. In that policy document was stated that (Department of the interior and Kingdom Relations, 2004, p. 34):

- $\quad$ The decentralized structure for crisis management has a rather informal and optional character with negative consequences for the decisiveness in crisis management

- Differing responsibilities lead to sometimes opposing interests and decisions. This phenomenon is called: "abrasive chains".

- Perceptions and expectations about tasks, roles, responsibilities of the participants and stakeholders in a crisis management process differ, especially during the response phase of a crisis.

These empirical observations, which are derived from several evaluation reports of crises and disasters and our current interpretations of past observations, support the analysis in this paper. As a result of these policies, disaster management in the Netherlands aims to strengthen central control over counter measures.

Crises in the Netherlands (and also in other countries) are, when possible, handled at a local level. In the Netherlands, during crises, the overall (administrative) command rests with the coordinating mayor of the local regional community and the operational command rests with the regional operational leader (Scholten, 2008). Although this regional structure aids in centralizing crisis management decision making, there are still limitations to this

\footnotetext{
${ }^{2}$ Although they become less dominant in times of crisis, these parochial perspectives are still relevant (Rosenthal 1993, Holsti 1990)

${ }^{3}$ Crises impose many special demands on leaders (Devitt, 2008, Boin et al. 2005, pp 10-15). Team leaders have a large impact on team building and team performance. The team development can influence the bureaupolitical behavior of team members. These aspects are left out of scope in this paper.
}

Proceedings of the $6^{\text {th }}$ International ISCRAM Conference - Gothenburg, Sweden, May 2009

J. Landgren and S. Jul, eds. 
centralized approach. For example:

- The operational leader has very limited formal hierarchical power. His duty is to coordinate, provide encouragement, resolve conflicts or bring them to the attention of the mayor (Scholten, 2008, Brainich von Brainich Felth, 2004 pp 74-78). The operational leader has limited "power to execute" in the operational policy team.

- Crisis management policy documents (often guidelines and handbooks) have no formal status in the sense that can be enforced by law. Boogers et al. (2003) define these documents as "informal regulation" and conclude that informal regulation in crisis management is inevitable, yet it can lead to great uncertainty on local administrative levels.

- During the first hour of repression (important, while during that first hour many casualties can be saved), collaboration takes place on the operational level. That coordination is not pre-structured and therefore depends on the qualities of the people at hand. During this first hour, there is almost no coordination by the mayor or the operational leader.

- Operational emergency services operate in general from a mono-disciplinary perspective (Scholten, 2008). Interdisciplinary organizations are underdeveloped; even within functional columns the degree of organization is often low (Boogers et al., 2003, p. 24).

\section{Figure 1. Empirical scan of Dutch Crisis Management}

For our analysis of the interaction between team members in crisis decision making, we want to model the behavior of the members of crisis management teams. For this modeling activity we will use theories of negotiation and of mental models. In the next section first a negotiation perspective on crisis decision making is explored, after which mental models are explored that govern the behavior of the crisis decision making participants.

\section{A NEGOTIATION PERSPECTIVE ON CRISIS DECISION MAKING}

In a bureaupolitical context, "where you stand depends on where you sit". The actors (in this case the members of a crisis management decision making team) have diverging and conflicting interests, and decisions are inherently compromises. The actors, however, are not able to solve the problem (in this case the crisis) singlehandedly. In such a context, the coordination process has the characteristics of a negotiation (Thompson, 2005, pp. 2-3; Mastenbroek, 1996, pp. 21-28; Pruitt and Carnevale, 2003, pp. 2-3). The team decisions are results of a negotiation process. The quality of the team decisions depends on the attitude of the team members towards the negotiation process, the negotiation strategy of the team members and the negotiation skills of the team members.

There are two main attitudes towards negotiations. Negotiations can be aimed at solving a fixed pie conflict (the winner gets the larger piece of the pie) or at reaching win-win agreements (Thompson, 2005, chapter 3 and 4). A competitive attitude is based on the belief that the negotiation situation is a fixed-pie: any gain for one negotiator leads automatically to a loss for the other negotiator(s). A collaborative attitude is based on the belief that so called win-win solutions, in which all participants win by the agreement, is possible.

A problem is more suitable for a win-win attitude in the negotiation when (Thompson, 2005, p. 71-72):

- There is a (large) number of issues to be brought into the negotiation

- There is a possibility to bring other issues in

- There is a possibility to make side-deals or side payments

- The negotiators have a difference in preferences across negotiation issues

Proceedings of the $6^{\text {th }}$ International ISCRAM Conference - Gothenburg, Sweden, May 2009

J. Landgren and S. Jul, eds. 
In crisis decision making processes there are many different issues, chances for side arrangements and differences in preferences between the team members. Crisis decision making processes are therefore, from a negotiation perspective, typical examples of possible win-win situations. So during crises, the optimal negotiation attitude is a win-win attitude.

Negotiation strategies depend on the concerns a negotiator has about his own outcomes and on the concerns a negotiator has about other's outcomes (dual concern model, Pruitt and Carnevale, 2003, p. 105; see figure 2). In the dual concern model, four negotiation strategies are presented. The strategies range from passive (low concern for own outcomes) to assertive (high concern for own outcomes) and from uncooperative (low concern for other's outcomes) to cooperative (high concern for other's outcomes).

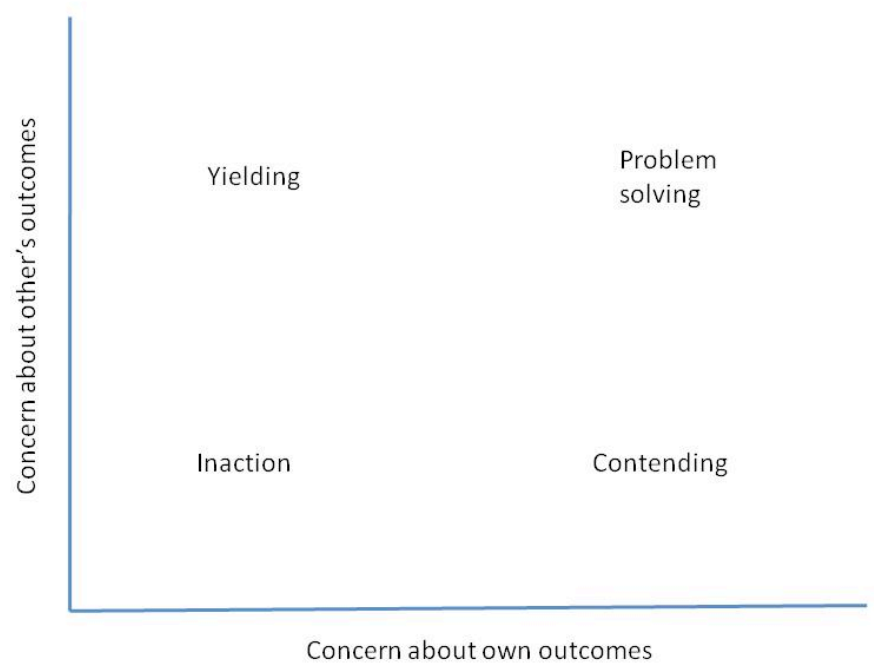

Figure 2. Dual Concern Model

(Pruitt and Carnevale, 2003, p. 105)

Win-win solutions with a high joint benefit (as in crisis management decision making processes) are particularly likely to be achieved when there is a high self concern and a high other concern (Pruitt and Carnevale 2003, p. 110). This means that for a win-win situation a collaborative negotiation strategy (problem solving) is most suitable to reach decisions. We will call this strategy "collaborative decision making".

\section{MENTAL MODELS IN COLLABORATIVE DECISION MAKING}

In order to understand situations we are in, we construct working models of the situations in our mind (JohnsonLaird, 1983, p.10). These models are in fact simplifications of reality, and are used to predict the behavior of the (physical) systems we are confronted with (Norman, in Gentner 1983, p 12) and to enable us to interact with these systems. A mental model represents a state of affairs. The structure of a mental model is identical to the structure of the state of affairs that the model represents (Johnson Laird, 1983, p 419). Mental models include key components (or tokens, as they are sometimes called) that correspond to entities in the world, relationships between those components and techniques for interacting with the system or processes (Westbrook, 2006). The mental model can be expressed as an effective procedure that could be carried out by a (simple) machine. In other words, mental models are "computable".

To be of use, a mental model cannot (directly) represent an infinite domain; it is therefore finite in size. In fact, perceptions of tasks and representations of complex systems can consist of multiple mental models. The greater the number of mental models that are used to define and perform a task, or the more complex the underlying mental model is and the poorer performance will be (Byrne, 2001).

According to Norman (in Gentner, 1983, p. 8), mental models are incomplete and unstable. Mental models are determined in an iterative process, during which a person adjusts his or her mental model, based on the performance of the system. Therefore, mental models have a dynamic character. Mental models have no firm boundaries: when another system looks the same, people use the same model. It is difficult to actually run mental models in one's mind (so objective testing is not possible).

Proceedings of the $6^{\text {th }}$ International ISCRAM Conference - Gothenburg, Sweden, May 2009

J. Landgren and S. Jul, eds. 
During crises, the decision makers are confronted with complexity, urgency and a high speed of events. To understand a crisis and predict the "cascade of events", decision makers will build a mental model of the situation and base their actions and opinions on that model. The mental models with which a person starts performing in a crisis situation are therefore based on former experience (and knowledge of comparable crises). During the crisis, the mental model of the situation is continuously evaluated and in doing so, a more fitting mental model of the present crisis will develop.

Crisis management decision making is not an individual activity. The decision making processes take place in multidisciplinary teams: crisis decisions are therefore based on a combination of mental models. This combination of individual mental models can be organized by combining these in a shared mental model. A shared mental model is an organized understanding of mental representations of knowledge that is shared by team members. Team effectiveness will improve if team members have an adequate shared understanding of the task, team and equipment (Klimoski, 2000). The level of model convergence positively influences team performance (Druskat, 2002). The 'sharedness' of mental models allows people to anticipate one another's actions and needs, an important feature when events in the team's environment are unpredictable or when frequent communication is difficult (Druskat, 2002) ${ }^{4}$, which is the case in a crisis situation.

Sharing mental models takes time, and time is a scarce element in crises management decision making processes. Therefore, on a meta-level, potential team members should be prepared for their role in crisis management decision making teams, so that sharing and combining of mental models takes as little time as possible. Druskat's research of team mental models in self managing teams helps us to define meta-models for collective decision making in multidisciplinary crisis management teams. In periods between crises, team members and teams can be trained in these aspects. To recapitulate: the creation of shared mental models improves when

- $\quad$ there is a belief of shared ownership

- $\quad$ self-evaluation and self correction takes place

- there is an active sharing of information, based on mutual respect

- team members are experienced in crisis management decision making

- there is an everyday organizational context that supports working in self managing teams

This paper focuses on decision making processes in decision making teams. There are four content domains of mental models for working in teams:

1. knowledge of equipment and tools used by the team

2. understanding about the work that the team is to accomplish, including its goals or performance requirements and the problems facing the team (task mental model)

3. awareness of team member characteristics, including representations of what individual members know and believe, their skills, preferences and habits (team member mental model) ${ }^{5}$

4. knowledge or beliefs of team members with regard to what are appropriate or effective processes (team interaction model)

This is schematically presented in figure 3 .

The team equipment mental model and the team task mental model represent the team-external factors organizational and situational awareness. The teamwork mental model represents the team-internal negotiation attitude and negotiation strategy of the individual team member. Therefore, for our analysis, the teamwork mental model (the combination of the team member mental model and the team interaction model) is relevant. A shared model of the adequate negotiation attitude and negotiation strategy supports an optimal negotiation process. In the next section we will define 5 negotiation mental models.

\footnotetext{
${ }^{4}$ Druskat specifically addresses self managing teams, so teams that are not manager-led. In a bureaupolitical environment, there is no one with an "overriding influence". Therefore, Druskat's research is relevant for this case.

${ }^{5}$ Druskat integrates items 3 and 4 in a "teamwork mental model".
} 




Figure 3. The elements of a shared mental model for teamwork

\section{MENTAL MODELS OF NEGOTIATION IN CRISIS DECISION MAKING}

A teamwork mental model describes how team members perceive each other and their interactions. When the team interaction is defined as a negotiation process, the teamwork mental model is a representation of the negotiation attitude and negotiation strategy of the individual team member (as well as his perception of the negotiation attitudes and negotiation strategies of the other team members).

Thompson has defined five mental models that negotiators use during negotiations (Thompson, 2005, pp. 175179):

1. The haggling model

The negotiation process is a struggle between parties, in which each is trying to obtain the biggest share of the pie.

2. Cost-benefit analysis

The negotiators see the negotiation process as a rational decision making process, in which everyone can map out a cost-benefit analysis and then maximize their returns.

3. Game playing

Negotiation is "a game of wits and nerve". Each person has his own interests in mind and, in many cases, a competitive motive. Everyone attempts to beat the other party at the game of negotiation.

4. Partnership

The participants want to nurture a long-term relationship. In many cases they are willing to make sacrifices in the name of creating long term goodwill.

5. Problem-solving

Participants consider negotiation to be the task of defining and solving a problem. In problem-solving negotiations, the participants sit at the same side of the table and attempt to solve a puzzle. In this model, participants need creativity and out-of-the-box thinking. There is a focus on collaborative aspects of the task.

In figure 4, a schematic overview of possible negotiation approaches in a team setting is presented.

Proceedings of the $6^{\text {th }}$ International ISCRAM Conference - Gothenburg, Sweden, May 2009

J. Landgren and S. Jul, eds. 


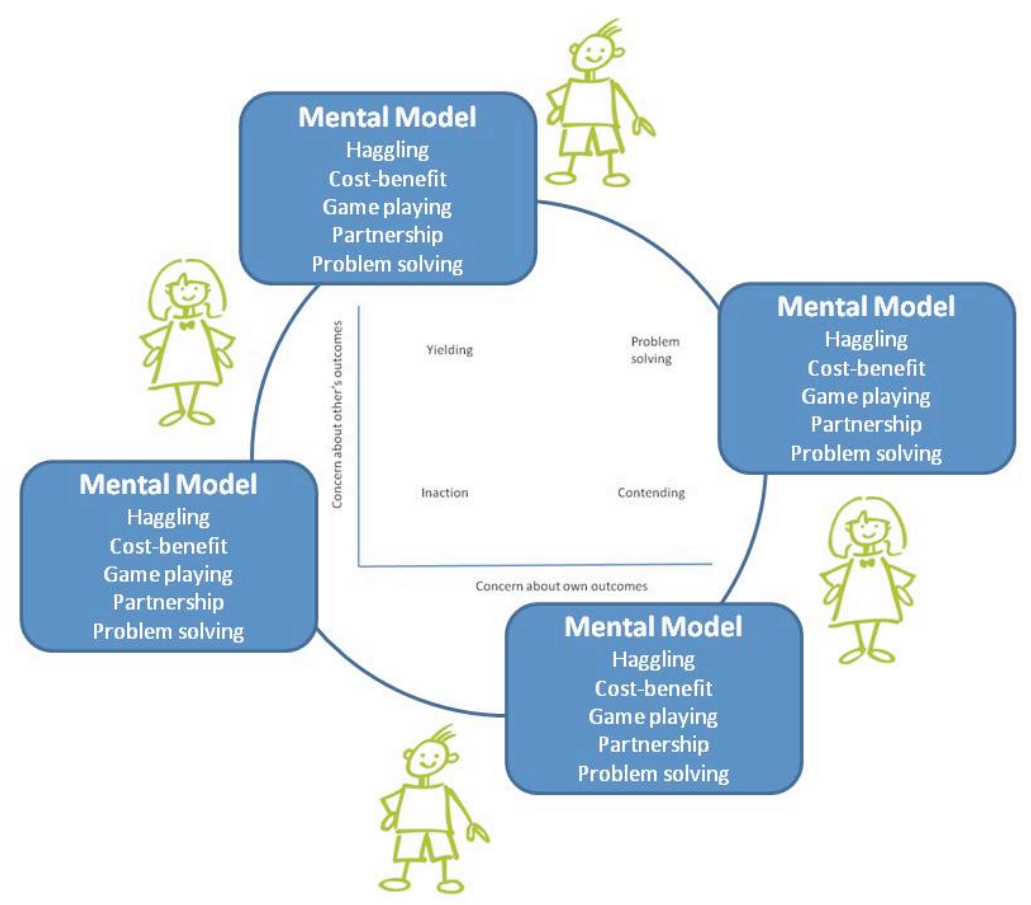

Figure 4. Shared Negotiation Model

Thompson and van Boven (2003) show that mental models of negotiators who reach optimal settlements, have more integrative elements (model 4 and 5) than mental models of negotiators who do not reach optimal settlements. Thompson and van Boven claim that negotiations in mixed-motive situations (note that crises are mixed-motive situations), an integrative approach by the negotiators is a necessity.

\section{CONCLUSION: TOWARDS A MENTAL MODEL DESIGN OF CRISIS MANAGEMENT DECISION MAKING}

The analysis of this paper of crisis decision making in a bureaupolitical context in terms of negotiation and mental models is based on available theories of negotiation, crisis management, and mental models, as well as experiences from practice (including those of the authors) in crises management. The main conclusions of the this analysis are:

- The Command \& Control adage does not hold for crisis decision making in multi-agency settings.

- Crisis decision making can be seen as a negotiation process in a bureaupolitical context.

- An assertive and cooperative approach (integrative mental model) of a negotiation process is most suitable for crisis decision making.

- In crisis decision making teams, there should be a shared integrative model of negotiation as dominant shared team model of crisis decision making.

- Crisis decision making teams will perform better if all members of the team take the underlying interests of the team members into account and if they do not lose sight of the underlying common goal of incident management.

On the basis of these analytical results, we pose the following thesis: Team performance in crisis management decision making improves when the participants use an integrative mental model of the decision making process that compares to a integrative mental model of negotiation. However, we hypothesize that in practice, at the start of a decision making process, team members typically use a competitive negotiation mental model. Thus, to improve decision making during crises, team members should be trained regularly in obtaining and maintaining an integrative mental model of joint decision making and tools to improve the decision making process during crises should support information sharing, knowledge retrieving and negotiation skills. 
Further research entails testing the main thesis and underlying hypothesis by means of a crisis decision making serious game. The conclusions of these experiments will lead to further insight in the coordination process during crises decision making and to specifications for supportive tools. The serious game itself can then be further developed into a training tool for crisis decision makers in a bureaupolitical context.

\section{ACKNOWLEDGMENTS}

The authors wish to thank the anonymous reviewers for their valuable feedback.

\section{REFERENCES}

't Hart, P., Rosenthal, U., Kouzmin, A. (1993), Crisis Decision Making, the centralization thesis revisited, in: Administration \& Society, 25(1):12-45.

Alberts, David S., Hayes, Richard E. (2005), Power to the Edge, Command and Control in the Information Age, CCRP publications series, www.dodccrp.org

Boin, A., 't Hart, P., Stern E., Sundelius, B. (2005), The Politics of Crisis Management, Public Leadership under Pressure, Cambridge University Press.

Boogers, M., Brandsen T., Tops, P.W. (2003), Rampen, Regels, Richtlijnen; de status van informele regelgeving op het gebied van rampenbestrijding, Universiteit van Tilburg.

Boven Leaf van, Thompson, Leigh (2003), A Look into the Mind of the Negotiator: Mental Models in Negotiation, Group Processes \& Intergroup Relations, 6(4):387 - 404.

Brainich von Brainich Felth, E.T. (2004), Het systeem van crisisbeheersing, bevoegdheden en verplichtingen bij de voorbereiding op en het optreden tijdens crises, Boom, Den Haag,.

Byrne, Ruth, Johnson-Laird, Phil (2000), http://www.tcd.ie/Psychology/Ruth_Byrne/mental_models/.

Devitt, K.R., Borodzicz, E. (2008), Interwoven Leadership: the Missing Link in Multi-Agency Major Incident Response, Journal of Contingencies and Crisis Management, 16(4): 208-216.

Druskat, Vanessa Urch, Pescosolido, Anthony T. (2002, The content of effective teamwork mental models in self-managing teams: ownership, learning and heedful interrelating, Human Relations, 55(3):293 - 314.

Duin, M.J. van (1992), Van rampen leren, Crisis Onderzoeksteam.

Gentner Dedre., Stevens, Albert L. (ed.) (1983), Mental models, Lawrence Erlbaum associates, London.

Gundel, S. (2005), Towards a new typology of crises, Journal of Contingencies and Crisis Management, pp 106-1 15 .

Helsloot, I. (2008), Coordination is a prerequisite for good collaboration, isn't it?, Journal of Contingencies and Crisis Management, editorial, 16(4):173-176.

Holsti, O.R. (1990), Psychological Dimensions of War, Newbury Park.

Johnson-Laird Philip N. (1983), Mental models, Harvard University Press, Cambridge.

Mastenbroek Willem (1999), Negotiating as Emotion Management, Theory, Culture \& Society, 16:49-73.

Mastenbroek, Willem (1996), Onderhandelen, Spectrum, Utrecht.

Mohammed, S., Klimoski R., Rentsch, J.R. (2000), The measurement of Team Mental Models: We have no Shared Schema, Organizational Research Methods, 3(2)123 - 165.

Peterson, Erika, Mitchell, Terence R., Thompson Leigh, Burr, Renu (2000), Collective Efficacy and Aspects of Shared Mental Models as Predictors of Performance over Time in Work Groups, Group Processes \& Intergroup Relations, 3(\#):296 - 316.

Pröpper, I.M.A.M. (1993), Inleiding in de organisatietheorie, VUGA, 's Gravenhage.

Pruitt, Dean G., Carnevale, Peter J. (2003), Negotiation in social conflict, Open University Press, Maidenhead.

Robert, B., Lajtha, C. (2002), A New Approach to Crisis Management, Journal of Contingencies and Crisis Management, 10(4):181-191.

Rosenthal, U. (1984), Rampen, rellen, gijzelingen, Crisisbesluitvorming in Nederland, De Bataafsche Leeuw, Amsterdam / Dieren.

Rosenthal, U., 't Hart, P. and Kouzmin, A. (1991), The bureaupolitics of crisis management, Public Administration, 69:211-233.

Rosenthal, U., Schendelen, M.P.C.M. van, Ringeling, A.B. (1987), Openbaar bestuur, organisatie, politieke omgeving en beleid, 4e druk, Samsom HD Tjeenk Willink, Alphen a.d. Rijn.

Santen, W. van, Janssen, A., Heijden, E. van der, Wijngaards, N. (2007), Scenario-Based Analysis for Decision Making: A Condition for Success in Crisis Management, Proceedings of the 4th International ISCRAM Conference, Delft, The Netherlands.

Scholten, A. (2008), Controlled Collaboration in Disaster and Crisis Management in the Netherland, History and Practice of an Overestimated and Underestimated Concept, Journal of Contingencies and Crisis Management, 16(4):195-207.

Thompson Leigh L. (2005; 2001), The Mind and Heart of the Negotiator, international edition, 3rd edition, Pearson Prentice Hall.

Proceedings of the $6^{\text {th }}$ International ISCRAM Conference - Gothenburg, Sweden, May 2009

J. Landgren and S. Jul, eds. 
Thompson, L., Hastie R. (1990), Social Perception in Negotiation, Organizational Behavior and Human Decision Processes, 47:98-123.

Ven, Josine van de, Rijk, Richelle van, Essens, Peter, Frinking, Erik (2008), Network Centric Operations in Crisis Management, Proceedings of the $5^{\text {th }}$ International ISCRAM conference.

Westbrook, Lynn (2006), Mental models: a theoretical overview and preliminary study, Journal of Information Science, 32.

Wybo, J.L., Latiers, M. (2006), Exploring complex emergency situations' dynamic: theoretical, epistemological and methodological proposals, International journal for Emergency Management, pp. 40-51.

Security policy

Department of the Interior and Kingdom Relations (2004), beleidsplan crisisbeheersing 2004-2007, June, (in Dutch).

Department of the Interior and Kingdom Relations (2006), Handboek rampenbestrijding (www.handboekrampenbestrijding.nl) (in Dutch).

Department of the Interior and Kingdom Relations (2007), Strategie Nationale Veiligheid, May, (in Dutch).

Department of the Interior and Kingdom Relations (2009), website netcentrisch werken, 2009 (www.crisisplein.nl) (in Dutch) 